\title{
Gestational Trophoblastic Disease: Review of Cases Managed at B P Koirala Memorial Cancer Hospital
}

\author{
Pariyar J, ${ }^{1}$ Shrestha B, ${ }^{1}$ Shrestha $\mathbf{J},{ }^{2}$ Rauniyar BP, ${ }^{2}$ Regmi SC ${ }^{2}$ \\ ${ }^{1}$ Gynecologic Oncology Unit, ${ }^{2}$ Medical Oncology Department, B.P. Koirala Memorial Cancer Hospital, Chitwan, Nepal.
}

Aims: This study was done to analyze the clinical presentation and management outcomes of gestational trophoblastic disease managed at B.P. Koirala Memorial Cancer Hospital, Chitwan, Nepal.

Methods: Descriptive study was conducted at B.P. Koirala Memorial Cancer Hospital. Case records of all gestational trophoblastic cases from January 2001 to December 2007 were analyzed regarding clinical details, investigations and treatment outcomes.

Results: Forty-five cases of 16 to 50 years (mean 29.1 years) had gestational trophoblastic disease, among which 19 (43\%) were of TibetoBurmese and 15 (33\%) Indo-Aryan ethnic group. Hydatidiform mole, invasive mole and choriocarcinoma were observed in 17 (37.8\%), six (13.3\%) and $22(48.8 \%)$ cases respectively. In seven cases (15.5\%) molar pregnancy had occurred in primigravida, seven cases (15.5\%) had previous molar pregnancy and in $16(35.5 \%)$ cases GTD had occurred following abortion. Vaginal bleeding was the commonest presentation and $26(57.8 \%)$ cases had anaemia. Eleven (24.5\%) cases had theca luteal cyst, $17(37.8 \%)$ had lung metastasis and $4(8.9 \%)$ had brain metastasis. Chemotherapy was administered in 34 (75.5\%) cases, among which $15(33.3 \%)$ received single agent and $18(40 \%)$ received multiagent chemotherapy. Hysterectomy was done in nine (20\%) cases. Brain irradiation was done in a case with brain metastasis. Five $(11.2 \%)$ cases with high WHO risk score left the hospital against medical advice. There were three $(6.6 \%)$ mortalities. Thirty-seven $(72.1 \%)$ cases were in remission and follow-up.

Conclusions: Early diagnosis of disease and proper management strongly influences the outcome of GTD. Even in disseminated state GTD can be cured.

Keywords: chemotherapy, choriocarcinoma, molar pregnancy, gestational trophoblastic disease.

\section{INTRODUCTION}

Gestational trophoblastic disease (GTD) represents a spectrum of histologically distinct pathologies including molar pregnancy, invasive mole, placental site trophoblastic tumour and choriocarcinoma. Invasive mole, placental site trophoblastic tumour and choriocarcinoma grouped as gestational trophoblastic tumours (GTT) has been referred to as "God's first cancer and man's first cure". ${ }^{1}$ Prior to 1956, GTT treatment usually involved surgical removal of the primary or metastatic lesions or perhaps radiotherapy. The treatment failure occurred in metastatic disease with fatal outcome in almost all patients. ${ }^{2}$ In 1956, at Maryland, the first patient with metastatic choriocarcinoma was cured by methotrexate. ${ }^{3}$

\section{CORRESPONDENCE}

Dr Jitendra Pariyar Gynecologic Oncology Unit, B.P. Koirala Memorial Cancer Hospital, Chitwan, Nepal.

Email: jpariyar@yahoo.com

Phone: 9841244359
The incidence of GTD in Japan and Mexico were 2/1000 and 2.5/1000 pregnancies respectively are three times higher than in Europe or North America (0.6 - 1.1/1000 pregnancies). ${ }^{4,5}$ The malignant potential of GTD is also higher in South Asia (10-15\%) compared to western countries (2-4\%). ${ }^{6}$ It is undetermined whether such differences are attributable to genetic characteristics or to shared cultural factors.?

The primary treatment of molar pregnancy is suction curettage, while that of choriocarcinoma is chemotherapy. Surgery is required in some patients. ${ }^{8}$

This study tried to explore the epidemiology, management and outcome of patients with GTD in Nepal.

The papers in this journal are published under the terms of the Creative Commons Attribution License. Users are allowed to read, download, copy, distribute, print, search, or link to the full texts of the articles in this journal without asking prior permission from the publisher or the author 


\section{METHODS}

This review was conducted at B.P. Koirala Memorial Cancer Hospital, Chitwan, Nepal from January 2001 to December 2007.

The case records of all the gestational trophoblastic diseases during the study period were analyzed regarding their identification, illness history, clinical examination, investigations, treatment and follow-up. The main outcomes were measured in terms of age, ethnicity, duration, parity, antecedent pregnancy, histopathology, investigations, treatment, follow-up and mortality associated with this disease. All the patients having trophoblastic disease with elevated ß-hCG, radiological or hispathological evidence of the disease were included in the study. Choriocarcinoma was diagnosed on the basis of histopathology or clinical presentation along with raised level of serum B-hCG and metastatic lesions detected by radiological examination. Statistical analysis was done using descriptive statistics: mean, range and standard deviation.

\section{RESULTS}

A total of 45 cases of gestational trophoblastic diseases (GTD) from 26 districts of Nepal received during the study period. There were 17 cases (37.8\%) of hydatidiform mole, six of invasive mole (13.3\%), four of persistent gestational trophoblastic tumour $(8.9 \%)$ and 22 patients $(48.8 \%)$ of choriocarcinoma (Table 1 ).

Table 1. Classification of GTD observed ( $n=45)$.

\begin{tabular}{lll}
\hline GTD Type & Number & Percentage \\
\hline $\begin{array}{l}\text { Hydatidiform } \\
(\mathbf{n}=\mathbf{1 7})\end{array}$ & Mole & \\
Complete Mole & 12 & 26.6 \\
Partial Mole & 1 & 2.2 \\
Persistent GTT & 4 & 8.9 \\
$\begin{array}{l}\text { Choriocarcinoma } \\
\text { (n=22) }\end{array}$ & & \\
HPE proven & 8 & 17.8 \\
$\begin{array}{l}\text { 个 Serum ß-hCG and } \\
\text { positive radiology }\end{array}$ & 14 & 31.0 \\
Invasion Mode & 6 & \\
& & 13.3 \\
\hline
\end{tabular}

The age of the patients ranged from 16 to 50 with a mean age of 29.1 years (SD 9.4 years). The highest percentage of GTD, $51.2 \%(n=23)$ was observed in $21-30$ years and choriocarcinoma was more common $(56.5 \%)$ in this age group. Magar women constituted $24.4 \%(n=11)$ of the
GTD with higher percentage $(54.4 \%, 6 / 11)$ of malignant progression as well. Nine-teen (43\%) belonged to TibetoBurmese ethnic group and 15 (33\%) to Indo-Aryan ethnic group. Malignant sequelae in Tibeto-Burmese and IndoAryans were $52.6 \%$ and $46.5 \%$ respectively.

The gestational period at presentation in 32 (71\%) cases was between two to five months, in $12(26.6 \%)$ cases it was less than two months and only in one $(2.2 \%)$ case it was more than five months (Table 2).

Table 2. Distribution of age, parity and gestational age at presentation $(n=45)$.

\begin{tabular}{lll}
\hline Characteristics & Number of Cases & Percentage \\
\hline Age & & \\
$<20$ years & 8 & 17.8 \\
$21-30$ years & 23 & 51.2 \\
$31-40$ years & 6 & 13.2 \\
$>40$ years & 8 & 17.8 \\
Parity & & \\
1 & 7 & 15.5 \\
2 & 11 & 24.5 \\
3 & 10 & 22.3 \\
$\geq 4$ & 17 & 37.7 \\
Gestational age & & \\
1 - 2 months & 12 & 26.6 \\
2 - 5 months & 32 & 71.2 \\
$>5$ months & 1 & 2.2 \\
\hline
\end{tabular}

In seven cases (15.5\%), molar pregnancy had occurred in the first conception; another seven cases (15.5\%) had previous molar pregnancy and $16(35.5 \%)$ cases of GTD had occurred following abortion (Table 3).

Table 3. Antecedent pregnancy $(n=45)$.

\begin{tabular}{lllll}
\hline $\begin{array}{l}\text { Obstetric } \\
\text { History }\end{array}$ & H. Mole & $\begin{array}{l}\text { Invasive } \\
\text { Mole }\end{array}$ & Choriocarcinoma & Total \\
\hline $\begin{array}{l}\text { Primigravida } \\
\text { Spontaneous }\end{array}$ & 4 & 1 & 2 & 7 \\
$\begin{array}{l}\text { abortion } \\
\begin{array}{l}\text { Induced } \\
\text { abortion }\end{array}\end{array}$ & 4 & 1 & 8 & 3 \\
$\begin{array}{l}\text { Molar } \\
\text { pregnancy }\end{array}$ & 4 & - & 3 & 13 \\
$\begin{array}{l}\text { Ectopic } \\
\text { pregnancy }\end{array}$ & - & - & 1 & 7 \\
$\begin{array}{l}\text { Term } \\
\text { pregnancy }\end{array}$ & 3 & 4 & 7 & 1 \\
\begin{tabular}{l} 
Total \\
\hline
\end{tabular} & 17 & 6 & 22 & 14 \\
\hline
\end{tabular}


The most common presenting symptom was vaginal bleeding (82.2\%) and 26 (57.8\%) patients had anaemia. Twenty-six (62\%) cases had uterus large for date, in 10 cases (24\%) uterine size corresponded with gestational age and six cases (14\%) had uterus small for date.

Fifty percent cases of molar pregnancy had ultrasonographic picture of snow storm pattern. Theca leuteal cyst was detected in 11 (24.4\%) of the cases. Seventeen (37.8\%) cases had lesions in chest X-ray, suggestive of lung metastasis which was further confirmed by CT scan among which only six (13.3\%) presented with haemoptysis. Four (8.9\%) cases had clinical features of cerebral involvement and $\mathrm{CT}$ scan of brain detected the metastatic lesions. Disseminated disease was detected radiologically in $7.5 \%$ $(3 / 40)$ of the cases.

Suction evacuation and follow-up with serial serum ß-hCG was the mainstay of treatment in molar pregnancy. Of 45 cases, 29 (64.4\%) had already undergone suction evacuation elsewhere and another six (13.3\%) were treated with suction evacuation only. Nine (20\%) underwent hysterectomy for invasive mole $(n=6)$ and complications like uterine perforation $(n=1)$ and excessive hemorrhage $(n=2)$.

Final histopathology, WHO modified risks score and the results of serum ß-hCG guided adjuvant treatment. The risk scoring was done taking into consideration: age, antecedent pregnancy, interval of antecedent pregnancy, serum ß-hCG level, largest tumour size, number of metastasis and prior chemotherapy. Cases with total score from 0 to 6 were regarded as low risk and $\geq 7$ high risk. Based on the above criteria, 22 (48.8\%) cases fell in low risk and $23(52.2 \%)$ cases fell in high risk group. Low risk group requiring chemotherapy received single agent and high risk group received multi-agent chemotherapy. Adjuvant chemotherapy was administered in 34 (75.5\%) cases among which 15 (33.3\%) underwent single agent chemotherapy with methotrexate; 18 (40\%) underwent multiagent chemotherapy with EMA-CO regimen and only $1(2.2 \%)$ high risk score case underwent MAC regimen. Chemotherapy was given until serum ß-hCG was negative or below normal value and then after continued for a further two to three cycles. One case required secondline chemotherapy with EMA-EP regimen. A case with brain metastasis required brain irradiation and intrathecal methotrexate. Single agent methotrexate resulted $86.6 \%$ $(13 / 15)$ complete remission after 3 to 8 cycles. Complete remission was obtained after 4 to 10 cycles of multiagent EMA-CO regimen in $73.7 \%(14 / 19)$ of cases.

Five (11.1\%) cases with disseminated disease and high WHO risk score left the hospital against medical advice. There were three $(6.6 \%)$ mortalities and remaining 37 (82.2\%) of the cases were in remission and follow-up (Table 4).
Table 4. Treatment and outcome $(n=45)$.

\begin{tabular}{ll}
\hline Treatment Modality & Number (\%) \\
\hline Surgical & \\
Uterine suction evacuation & $35(64.4 \%)$ \\
Abdominal hysterectomy & $9(20 \%)$ \\
$\begin{array}{l}\text { Surgical resection } \\
\text { (nephrectomy) }\end{array}$ & $1(2.2 \%)$ \\
Chemotherapy & $34(75.5 \%)$ \\
Single agent ( MTX+FA Regimen) & $15(33.3 \%)$ \\
Multi-agent (EMA-CO, MAC Regimen) & $20(44.4 \%)$ \\
Complete Remission (CR) & $37(82.2 \%)$ \\
Left against medical advice (LAMA) & $5(11.2 \%)$ \\
Mortality & $3(6.6 \%)$ \\
\end{tabular}

\section{DISCUSSION}

This study revealed more cases of GTD among TibetoBurmese ethnic group with higher incidence of malignant sequelae as well which is similar to observation made in Hawaii study where higher incidence of GTD and metastatic disease was observed among East Asian countries (Japan, Philippines). ${ }^{9}$ The highest frequency of GTD observed among 21 - 30 years in the study was reported as significantly lower incidence in the other study. ${ }^{9}$ However, mean age is consistent with other studies.

With regards to etiological factors, nulliparity was associated with molar pregnancies in several studies. ${ }^{8,10}$ But, in present study less percentage of women had GTD in the first pregnancy. Previous history of hydatidiform mole is another well-established risk factor. ${ }^{11}$ Seven (15.5\%) of cases in our study had molar pregnancy in the past among which three were found to have metastatic disease. In 50 $\%$, choriocarcinoma is preceded by hydatidiform mole; in $25 \%$ it follows abortion or ectopic pregnancy and in remaining $25 \%$, delivery of a normal fetus. ${ }^{12}$ Similar risk factors were observed for choriocarcinoma.

Experience from England and the United States reveals that complete mole is being diagnosed earlier in gestational age. ${ }^{4}$ A study done in Saudi Arabia showed that $50 \%$ of the patients are diagnosed during their first trimester and present infrequently with the classical signs and symptoms. ${ }^{13}$ Majority (71\%) of GTD in our study presented with 2-5 months of amenorrhea which is consistent with classical description but is not consistent with recent studies from US, England and Saudi Arabia.

Although there have been advances in development of effective chemotherapy to improve survival rate, surgery has crucial role in management of GTD. In family completed elderly patients, abdominal hysterectomy offers advantage 
of simultaneous evacuation and sterilization. Additionally, hysterectomy has shown to reduce the risk of malignant sequelae to approximately $3.5 \%$ from $20 \%$ anticipated for patients treated with suction curettage. ${ }^{8}$ Nine $(20 \%)$ of our patients, with family complete, underwent hysterectomy mainly for invasive mole for the advantage of sterilization, reducing morbidity and also reducing malignant squeal.

Cure rates of $90-100 \%$ have been reported in patients with non-metastatic and low-risk metastatic disease if treated appropriately. ${ }^{14-16}$ In cases having low risk score, single agent chemotherapy with methotrexate resulted $86.6 \%$ complete remission and in cases having metastatic disease and high risk score, EMA-CO resulted in $73.7 \%$ complete remission. Overall cure rate achieved in our study is slightly lower than that of other studies.

\section{CONCLUSIONS}

Gestational trophoblastic disease was more prevalent among young women of Tibeto-Burmese ethnicity with higher rate of progression into malignancy. Early diagnosis of disease and proper management strongly influenced the outcome of GTD and it is potentially curable even in disseminated state. The frequency of trophoblastic disease could not be obtained as our hospital is the national cancer hospital without obstetrical services. Thus, a larger multicentre study involving obstetrical department is required.

\section{REFERENCES}

1. Hertig AT. Human trophoblast. Springfield, IL: Charles C Thomas, 1968.

2. Hammond CB. Gestational trophoblastic neoplasms: history of the current understanding. Obstet Gynecol Clin N Am. $1988 ; 15: 435-41$

3. Li MC, Hertz R, Spencer DB. Effect of methotrexate therapy on choriocarcinoma and chorioadenoma. Pro Soc Exp Biol Med. 1956;93:361-6.
4. Moodley M, Tunkyi K, Moodley J. Gestational trophoblastic syndrome: an audit of 112 patients. A South African experience. Int J Gynecol Cancer. 2003;13(2):234-9.

5. Lara FM, Alvarado AM, Candelaria M, Arce CS. Gestational trophoblastic disease: experience at National Institute of Cancerology. Ginecol Obstet Mex. 2005;73(6):308-14.

6. Rustin GJS. Trophoblastic disease. In: Shaw RW, Soutter WP, Stanton SL, editors.Gynaecology. 3rd ed. Edinburgh: Churchill Livingstone. 2002;248-59.

7. Mungan T, Kuscu E, Dabakoglu T, Senöz S, Uğur M, Cobanoglu O. Hydatidiform mole clinical analysis of 310 patients. Int J Gynaecol Obstet. 1996;52(3):233-6.

8. Sivanesaratnam V. The management of gestational trophoblastic disease in developing countries such as Malaysia. Int J Gynaecol Obstet.1998;60:105-9.

9. Burger RA, Creasman WT. Gestational trophoblastic Neoplasia. Disaia PJ, Creasman WT, editors. Clinical Gynecologic Oncology. 6th ed. St. Louis : Mosby Inc. 2002;185-210.

10. Remy JC, McGlynn J, McGuire. Trophoblastic disease: 20 years experience. Int J Gynaecol Obstet. 1989; 28(4):355-60.

11. Sand PK, Lurain JR, Brewer JI. Repeat gestational trophoblastic disease. Obstet Gynecol. 1984; 63(2): 140-4.

12. Bhatla N. Gestational trophoblastic disease. In: Bhatla N, editor. Jeffcoate's Principles of Gynaecology. 5th ed. London : Arnold. 2001;225-37.

13. Rice LW, Berkowitz RS, Lage JM, Goldstein DP, Bernstein MR. Persistent gestational trophoblastic tumour after partial hydatidiform mole. Gynecol Oncol. 1990;36(3):358-62.

14. Goldstein DP, Berkowitz RS. Current management of complete and partial molar pregnancy. J Reprod Med Obstet Gynecol. 1994;39(3):139-46.

15. Felemban AA, Bakri YN, Alkharif HA, Altuwaijri SM, Shalhoub J, Berkowitz RS. Complete molar pregnancy: clinical trends at King Fahad Hospital, Kingdom of Saudai Arabia. J Reprod Med Obstet Gynecol. 1998;43(1):11-3.

16. Khaskheli M, Khushk IA, Baloch, Shah H. Gestational trophoblastic disease: experience at a tertiary care hospital of Sindh. J Coll Physicians Surg Pak. 2007;17(2):81-3. 